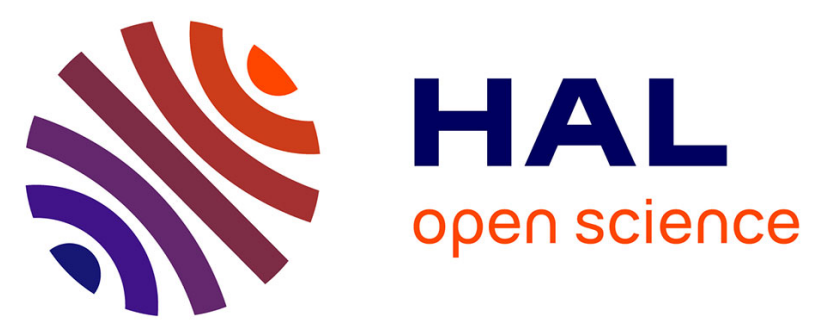

\title{
Effects of Tropical Climate and Language Format on Imagery Ability Among French-Creole Bilinguals
}

Nicolas Robin, Frédéric Anciaux, Guillaume R. Coudevylle, Nicolas Robin Frederic Anciaux ${ }^{2}$, Guillaume R Coudevylle ${ }^{1}$

\section{- To cite this version:}

Nicolas Robin, Frédéric Anciaux, Guillaume R. Coudevylle, Nicolas Robin ${ }^{1}$, Frederic Anciaux ${ }^{2}$, et al.. Effects of Tropical Climate and Language Format on Imagery Ability Among FrenchCreole Bilinguals. International Journal of Bilingual Education and Bilingualism, 2020, pp.1-15. 10.1080/13670050.2019.1709412 . hal-02439861

\section{HAL Id: hal-02439861 https://hal.science/hal-02439861}

Submitted on 14 Jan 2020

HAL is a multi-disciplinary open access archive for the deposit and dissemination of scientific research documents, whether they are published or not. The documents may come from teaching and research institutions in France or abroad, or from public or private research centers.
L'archive ouverte pluridisciplinaire HAL, est destinée au dépôt et à la diffusion de documents scientifiques de niveau recherche, publiés ou non, émanant des établissements d'enseignement et de recherche français ou étrangers, des laboratoires publics ou privés. 
Effects of Tropical Climate and Language Format on Imagery Ability Among French-Creole Bilinguals

Nicolas Robin¹, Frederic Anciaux² and Guillaume R. Coudevylle².

${ }^{1}$ Université des Antilles, Faculté des Sciences du Sport, Pointe-à-Pitre, France.

${ }^{2}$ College of Teaching Profession and Educational of the Academy of Guadeloupe, France.

Correspondence concerning this article should be adressed to Nicolas Robin, Laboratoire

"Adaptation au Climat Tropical, Exercice \& Santé" (UPRES EA 3596), Campus Fouillole, BP 592, 97159, Pointe-à-Pitre Cedex, France.

Contact: robin.nicolas@hotmail.fr

Running head: TROPICAL CLIMATE AND IMAGERY AND BILINGUALISM

Word count: 6200 


\begin{abstract}
This study examined how a tropical climate (i.e., hot and wet climatic environment) and different language instructions, in French and in Creole, could affect imagery ability on French-Creole bilingual in the French West Indies. Participants were divided into two groups: Half of them completed the French Movement Imagery Questionnaire (MIQ-F), the others realized the Creole version (MIQ-C), in Neutral Climate (NC) then in Tropical Climate (TC). The results of this original study showed that participants had lower visual and kinaesthetic MIQ-F and kinaesthetic MIQ-C imagery scores, but had higher visual MIQ-C imagery scores, in TC than in NC. Poor imagers had significant lower kinaesthetic MIQ-F, and better visual MIQ-C imagery scores in TC than in NC. The results of this study suggested that imagery language instruction can modulate the influence of tropical climate on imagery ability. The difference between Creole and French language effects on cognition as imagery is discussed. Keywords: Imagery ability, bilingual, French-Creole, tropical environment
\end{abstract}


Effects of Tropical Climate and Language Format on Imagery Ability Among French-Creole Bilinguals

Guadeloupe is a French West Indies island, characterized by a tropical climate (i.e., hot and wet climatic environment), where the communication is made in French and in Creole. The Creole is a language that is known to have particular links with mental imagery (Anciaux, 2003), which can be influenced, in its turn, by heat (Robin, Coudevylle, Hue \& Sinnapah, 2017). The aim of this original study was to evaluate whether Tropical Climate (TC) differently influences participants' imagery ability (i.e., ease or difficulty to generate and use images) when using Creole versus French mental imagery questionnaires. After having specified Mental Imagery (MI), the relation between the latter and Creole will be addressed. Then, the influence of TC, and particularly heat, on cognition and language, will be evoked in the light of the Global Workspace Theory (Baars, 1997). According to this theory, the limited cognitive capacity and the resources solicited by the thermal stress (Hocking, Silberstein, Lau, Stough, \& Roberts, 2001) would deteriorate the performance in the cognitive tasks such as MI (Robin \& Coudevylle, 2018).

MI is a conscious process that reflects a real experience in that different senses (e.g., sense of smell, sight, taste, hearing) are experienced in the mind without actually experiencing the real thing (White \& Hardy, 1998). This popular and frequently mental technique is widely used in sport, exercise, learning and rehabilitation settings to serve a number of outcomes such as enhancing motivation and self-efficacy, improving skills and strategies, regulating arousal and anxiety, and facilitating recovery (Guillot \& Collet, 2008). MI is a function of experience interacting with genetic variability and it is now well established that the effectiveness of MI depends upon one's capacity to generate mental images (Seiler, Monsma, \& Newman-Norlund, 2015). According to Hall, Bernoties, and Schmidt (1995), the two most common sensory modes of generating images are visual (i.e., what an individual sees) and 
kinaesthetic (i.e., feeling or polysensory experience of the body while performing a movement). A comprehensive yet inexpensive method of screening participants' visual and kinaesthetic imagery abilities is the use of self-report questionnaires. Using the Hall and Pongrac (1983) Movement Imagery Questionnaire (MIQ), which allows differentiating poor from good imagers on the basis on simple movements (e.g., put the arm above the head and lower it with the closed fist), many authors observed that good imagers improve their acquisition in learning tasks (Goss, Hall, Buckolz, \& Fishburne, 1986). The authors proposed that good imagery ability facilitates the memory information encoded in the representation of actions. Individuals with higher levels of imagery ability "good imagers" experience greater benefits from imagery compared with their lower level counterparts "poor imagers" (e.g., Toussaint, Robin \& Blandin, 2010; Robin \& Coudevylle, 2018; Williams, Cooley, \& Cumming, 2013). Indeed Robin et al. (2007) observed that motor imagery (i.e., to visually imagine realizing a tennis serving return focusing attention on the ball trajectory and the target) improved the precision of the task, and that this improvement was better in good imagers than in poor imagers. Moreover, the language is a factor that can influence movement imagery ability. For example, Anciaux, Alin, Leher, and Mondor (2002), while using a Creole version of the MIQ (MIQ-C), observed that bilingual subjects aged from 14 to 16 reported more vivid visual images than participants aged from 11 to 13 whereas there was no difference in French with the French version of the MIQ (MIQ-F). Indeed, the language system is deeply intertwined to the motor system (Stins, Marmolejo-Ramos, Wenker, Hulzinga, \& Cañal-Bruland, 2017), its processing is embodied (Rueschemeyr, Lindemann, van Rooij, van Dam, \& Bekkering, 2010) and shares neural structures with other cognitive activities as mental imagery or conceptual knowledge (Gallese \& Lakoff, 2005).

In Guadeloupe, the communication is made in French and in Creole. The "Creole" term, at first, referred to the inhabitants of colonial territories, born in the islands. Afterwards, 
it applied to the manners to speak (Véronique, 2000). Every language occupies a particular status and plays a specific role in the daily sparring matches (Anciaux et al., 2002). French is the official language, that of the information and the education (Anciaux, 2007). Creole represents the vernacular language, in other words, the spoken language inside the West Indian community (Ferguson, 1959). According to Anciaux (2003), it is cultural and dominated by the people language, the symbol of the identity and the partner of the private or familiar conversations. The coexistence in the same community of two linguistic codes of which the statutes are uneven, as it is the case in the French overseas departments, is translated by a diglossia (Fergusson, 1959) or bilingualism (Hamers \& Blanc, 2000). Nevertheless, that deprives nothing of the fact that the great majority of the inhabitants of Guadeloupe are French-Creole bilinguals (Massina et al., 2000). In this specific context, Guadeloupean people build themselves linguistic and driving behavior, attitudes and mental representations in correlation with, on one hand French, and on the other hand Creole (Anciaux et al., 2002). The bilingualism allows the organization of a system of the reality and the information appropriate to each of the languages (Massina et al., 2000; Mishra, 2018). In Guadeloupe, the education is mainly driven in French. However, psycholinguistic studies highlighted the positive effects of using Creole on learning and performances (Durizot JnoBaptiste, 1996), participation of the pupils (Giraud, Gani, \& Manesse, 1992), clarification of the instructions (Vasseur, 1997), application of the acquired knowledge (Gauvin, 1977) and engender faster and more successful cognitive learning (Giraud et al., 1992). The Creole officially entered the school by obtaining in 2001 the status of regional language and that of the object of optional education (Anciaux, 2007). A study on the linguistic imagination of Creole speakers supports the idea that the Creole is a language made by images or embellished with images because it is mainly transmitted orally (Michelot, 2000). Previous studies showed an effect of the language on the mental imagery movement capacities, the 
value of imaging of the words and the performances of motor reminding with French-Creole bilinguals (Anciaux, 2003; Anciaux et al., 2002; Anciaux, Caliari, Alin, Le Her, \& Fery, 2005). For example, the language of presentation of the instructions seems to influence the evocation of mental images to certain French-Creole bilinguals, and therefore, to increase the memory capacities and the motor reminding of series of actions (Anciaux, 2007). These singular language effects could also be situated at the level of the mobilization of the motivation, attention, emotion, memory, and cognition. Language mediates not only the social relationship systems, but also the control of cognitive processes (Ardila \& Ramos, 2010). The latest authors proposed that using one additional language to communicate is reflected in the pattern of brain organization and activity. Indeed, changes in the brain of bilingual individuals have been reported by Mechelli and collaborators (2004) who found that learning a second language increases the density of grey matter in the left inferior parietal cortex and influence cognition (see Bialystok, 2017 for a review). For examples, studies demonstrated higher anticipatory control in the occulomotor domain (Singh \& Mishra, 2015), inhibitory control and attention in proficient bilinguals (Mishra, 2018). Bilingual people also have to be able to switch between languages when required (De Baene, Duyck, Brass, \& Carreiras, 2015). The ability to select the appropriate language (i.e., Creole or French) and switch between theses languages involves general executive processing (Bialystok, 2017), is regarded as a linguistic ability dependent upon frontal lobe activity (Abutalebi \& Green, 2007; Hernandez, Dapretto, Mazziotta, \& Bookheimer, 2001) and is increased with second language proficiency (Zhao et al., in press). The Creole being a language that is spoken most of the time in TC, it seems important to take this particularly hot environment into account.

The impact of the environmental temperature on the cognitive performances is fairly well documented (for a review, see Gaoua, 2010). Many authors observed that heat stress is associated with decreased performance across multiple tasks (Berg et al., 2015; Coudevylle, 
Sinnapah, Robin, Collado, \& Hue, 2019; Qian et al., 2015). For example, Ramsey and Kwon (1992) confirmed that simple mental tasks show little, if any, decrement in the heat, and added that more difficult tasks (perceptual motor tasks) show the onset of decrements in the range between $30-33^{\circ} \mathrm{C}$. The global workspace theory (Baars, 1997) can be proposed as a possible explanation of these results. This theory suggests that consciousness enables multiple neuronal networks to compete or cooperate in solving problems in different environmental conditions (Gaoua, 2010). Humans have a limited cognitive capacity due to different stimuli competing for the limited conscious access to the vast global workspace. For example, Hocking et al. (2001) suggested that the performance in the cognitive tasks would deteriorate when the total resources are insufficient for both the task and the thermal stress. Moreover, Qian et al. (2015) proposed that heat stress has a potential fatigue-enhancing effect when individual is performing highly cognition demanding attention task. In addition, numerous works on the TC showed that this climate could be particularly disabling and increases thermal discomfort (e.g., Coudevylle, Sinnapah, Popa-Roch, Hue, \& Robin, in press). Thermal comfort/discomfort is the condition of mind that expresses satisfaction or dissatisfaction with the thermal environment, which is generally assessed by scales (Xiong, Lian, Zhou, You, \& Lin, 2015). Gaoua (2010) observed that impairment in working memory without alteration in attentional process during heat exposure was shown. The latter author suggested that exposure to a hot environment is a competing variable to the cognitive processes. Moreover, we noted that some studies reported gender differences related to heat. For example, Wyon, Andersen, and Lundqvist (1972) reported that females could better withstand the negative effects of heat stress than males, and Lan, Lian, Liu, and Liu (2008) found that males prefer cooler room temperature than females who furthermore are less sensitive to humidity. It seems that heat stress is associated with decreased cognitive and psychomotor performance across multiple tasks, sometimes with gender effects, but to date, 
the effect of a particularly hot environment on mental imagery ability and different language instructions remains unstudied to our knowledge.

The aim of this original study was to evaluate whether TC differently influences MIQ scores (Creole vs. French versions) upon participants' imagery ability. On the basis of the global workspace theory, on the fact that the performance in the cognitive tasks could deteriorate due to the thermal stress (Hocking et al., 2001), and on Guillot, Louis, and Collet (2009) who observed that poor imagers need to recruit more mental resources in order to build a vivid representation of the movements, we predicted that the imagery ability of good imagers would be less affected by the deleterious effect of hot and wet climatic environment than that of poor imagers. Moreover, we presumed that because the Creole is an image language learned in tropical place, the representation of action would be easier in TC than in Neutral Climate (NC) when using Creole imagery instructions. We also expected that MIQ scores would be higher in TC than in NC when instructions were given in Creole rather than French. Finally, although gender effect is generally not observed in the MIQ, TC and more particularly heat is likely to produce one and to enhance sensation of fatigue in males. Therefore, the evaluation of the influence of TC on MI should be accompanied by the measures of the fatigue, comfort and thermal sensations in order to control that these factors do not differently influence participants, according to their gender, in each environmental condition (i.e., $\mathrm{NC}$ and TC).

\section{Materials and methods}

\section{Participants}

One hundred and ten self-declared right-handed participants gave their informed consent to participate in the study $\left(M_{\text {age }}=31.01\right.$ years, age range: $26-35$ years, $\left.S D=2.47\right)$. All were French-Creole bilingual Guadeloupean primary school teachers (in the French West Indies) living in the tropical environment throughout the year. They teach all subjects to 
pupils from 2 to 11 years old and have the habilitation to teach Creole. As many factors can influence mental performance, before each session, participants completed a control selfreport questionnaire evaluating their consumption of medicine, drug, alcoholic and nonalcoholic drinks in the $24 \mathrm{~h}$ preceding each experimental trial. Ninety-six participants were retained (good and poor imagers) and divided into two groups. Fourteen participants were excluded being in intermediate categories (see Robin et al., 2007). In the first group, 48 participants (33 females and 15 males) were retained $\left(M_{\text {age }}=31.52\right.$ years, $S D=2.46$ years) with regard to their MIQ-C scores: Poor imager $(N=24$; scores $<23$, mean $<2.5)$ and good imager $(N=24$; scores $>41$, mean $>4.5)$ groups. Forty-eight other participants (33 females and 15 males) were retained ( $M_{\text {age }}=30.41$ years, $S D=2.37$ years) with regard to their MIQ-F scores: Poor imager $(N=24$; scores $<23$, mean $<2.5)$ and good imager $(N=24$; scores $>41$, mean > 4.5) groups.

\section{Material}

Questionnaire. During each experimental session, all the participants completed the French: MIQ-F (Lorant \& Gaillot, 2003) or Creole: MIQ-C (Anciaux et al., 2002) translated and validated versions of the Movement Imagery Questionnaire (MIQ, Hall \& Pongrac, 1983). The construct validity (internal consistency of visual and kinaesthetic scales were respectively 0.87 and 0.91 for the MIQ-F; 0.89 and 0.88 for the MIQ-C and corresponded to composite reliability scores, see McNeish, 2018 for similar procedure) and the test-retest reliability ( 0.83 for the two) of the available French and Creole versions were duly validated. Each version of the MIQ consists in 18 items that assess individual visual (9 items) and kinaesthetic ( 9 items) imagery abilities. The actions to be performed, which are similar in the two scales, involve a variety of arm, leg, and whole body movements (e.g., raising and lowering the right knee or performing a front roll on a mat and finishing in standing position). At the outset and for each item, participants listen to an audio description of the movement to 
be carried out. After that, the participants actually perform the movement and are then asked to either visually or kinaesthetically imagine it. Following this step, it was written in the MIQ: "Now, consider the ease or difficulty with which you were able to do this mental task", and participants rate their ease of imaging on a 7-point Likert-type scales for the visual imagery (from $1=$ very hard to see to $7=$ very easy to see $)$ or on an other 7 -point Likert-type scales for the kinaesthetic imagery (from $1=$ very hard to feel to $7=$ very easy to feel). Then, the items for each subscale are added, a higher score representing a greater ease of imaging.

\section{Procedure}

The present experiment was conducted on a rectangular room $(5 \times 7$ meters $)$. Sessions were realized in $\mathrm{NC}$ (mean temperature $=24.07^{\circ} \mathrm{C}, S D=0.69$; and humidity $=47.2 \% \mathrm{rH}, S D$ $=3.7$ ) or $\mathrm{TC}$ (mean temperature $=31.12^{\circ} \mathrm{C}, S D=0.29$; and humidity $=73.4 \% \mathrm{rH}, S D=6.3$ ). Temperature and humidity were recorded with a thermohygrometer Fisherbrand (humidity precision $\pm 5 \% \mathrm{rH}$ from 35 to $75 \% \mathrm{rH}$, and $\pm 8 \% \mathrm{rH}$ beyond; temperature precision $\pm 0.1^{\circ} \mathrm{C}$ ). TC is characterized by consistently high monthly temperatures, often exceeding $18^{\circ} \mathrm{C}$ throughout the year, and rainfall that exceeds evapotranspiration for at least 270 days per year (Salati, Lovejoy \& Vose, 1983). According to the annual climatic bulletin 2015, these values varied across the day. For example, between 10:00 am and 04:00 pm, indoor mean temperature can frequently reach $31^{\circ} \mathrm{C} \pm 2^{\circ}(\mathrm{rH} 80 \% \pm 10 \%)$, but in air-conditioned rooms the mean temperature generally measured is $24^{\circ} \mathrm{C} \pm 1^{\circ}(\mathrm{rH} 45 \% \pm 5 \%)$.

All participants performed the procedure with a one-week interval between sessions (i.e., one in $\mathrm{NC}$ and one in TC). These conditions were presented in a randomized order. During each session, the participants completed the control questionnaire, indicated their feeling of fatigue, thermal and comfort sensations and realized the MIQ-F or the MIQ-C.

\section{Data analysis}

For each participant, visual and kinaesthetic imagery scores at the MIQ-C or MIQ-F 
were calculated and verified that all variables were normally distributed (Shapiro-Wilk test). The dependent variables for the MIQ-C and MIQ-F were submitted to separate ANOVAs (with repeated measures on the last factor) contrasting 2 imagery ability (good imagers vs. poor imagers $) \times 2$ gender (female vs. male $) \times 2$ temperature conditions $($ TC vs. NC), with imagery ability and gender as within-subjects factors and temperature condition as a betweensubjects factor. As sensation of fatigue and thermal comfort and sensation can influence cognitive process in function of environmental conditions, assessment then analyses on these 3 control variables were realized. Feeling of fatigue was recorded on 7-point scale ranging respectively from 1 "fully alert" to 7 "completely exhausted". Moreover, participants were asked to rate both their thermal comfort on a 4-point scale (from 1, comfortable, to 4, very uncomfortable) and their thermal sensation on a 7-point scale (from -3 , cold, to +3 , hot). The averaged scale scores for the feeling of fatigue and thermal comfort and sensation were submitted to ANOVAs (with repeated measures on the second factor) using the gender (female vs. male) as between-participants factor and the temperature conditions (TC vs. NC) as a within-participants factor. All significant main effects and interactions were broken down using the post-hoc Newman-Keuls technique. Alpha was set at .05 for all analyses and effect sizes $\left(\eta_{\mathrm{p}}{ }^{2}\right)$ were indicated. The software package Statistica (12, 64-bit) was used for all analyzes.

\section{Results}

\section{Preliminary analysis on control variables: feeling of fatigue and thermal comfort and} sensation

The ANOVAs revealed that there was no gender main effects or interactions between gender and temperature condition (TC vs. NC) for feeling of fatigue, thermal comfort and sensation. However, main effects of temperature condition were observed. Post-hoc Newman- 
Keuls tests revealed that the participants had higher feeling of fatigue, lower thermal comfort and felt hotter in TC than in NC (main results are summaries in Table 1).

Table 1 near here

\section{MIQ-F visual imagery analysis}

The ANOVA revealed a significant main effect of imagery ability, $F(1,44)=1519.1$, $p<.01, \eta_{\mathrm{p}}{ }^{2}=0.97$. Post-hoc Newman-Keuls test revealed that poor imagers had worse visual imagery MIQ-F mean scores than good imagers, which correspond to our criteria of inclusion. Moreover, the ANOVA revealed a significant main effect of climate, $F(1,44)=121.33, p<$ $.01, \eta_{\mathrm{p}}{ }^{2}=0.73$. Post-hoc Newman-Keuls test revealed that participants had worse visual imagery MIQ-F mean scores in TC than in NC (see Figure 1). However, the ANOVA did not reveal any significant main effect of gender, $F(1,44)=0.006, p=.938, \eta_{\mathrm{p}}{ }^{2}=0.00$ or interactions between imagery ability and gender, $F(1,44)=1.057, p=.309, \eta_{\mathrm{p}}{ }^{2}=0.02$, climate condition and gender, $F(1,44)=0.018, p=.891, \eta_{\mathrm{p}}{ }^{2}=0.00$, climate condition and imagery ability, $F(1,44)=2.357, p=.132, \eta_{\mathrm{p}}{ }^{2}=0.05$, and climate condition and imagery ability and gender, $F(1,44)=0.028, p=.867, \eta_{\mathrm{p}}{ }^{2}=0.00$.

Figure 1 near here

\section{MIQ-F kinaesthetic imagery analysis}

The ANOVA revealed significant main effects of imagery ability, $F(1,44)=615.5, p$ $<.01, \eta_{\mathrm{p}}{ }^{2}=0.93$, and climate, $F(1,44)=12.308, p<.01, \eta_{\mathrm{p}}{ }^{2}=0.22$. Post-hoc Newman-Keuls tests revealed that participants had worse kinaesthetic imagery MIQ-F mean scores in TC than in NC, and that poor imagers had worse kinaesthetic imagery MIQ-F mean scores than good 
imagers. Moreover, the ANOVA revealed a significant interaction between climate condition and imagery ability, $F(1,44)=9.011, p<.01, \eta_{\mathrm{p}}{ }^{2}=0.17$. Post-hoc Newman-Keuls test revealed that poor imagers had significant lower kinaesthetic imagery MIQ-F mean scores in TC than in NC (Figure 2). However, the ANOVA did not reveal any significant main effect of gender, $F(1,44)=0.539, p=.466, \eta_{\mathrm{p}}^{2}=0.01$, or interactions between imagery ability and gender, $F(1,44)=0.207, p=.651, \eta_{\mathrm{p}}^{2}=0.00$, climate condition and gender, $F(1,44)=0.523$, $p=.473, \eta_{\mathrm{p}}{ }^{2}=0.01$, and climate conditions and imagery ability and gender, $F(1,44)=1.512$, $p=.225, \eta_{\mathrm{p}}^{2}=0.03$

Figure 2 near here

\section{MIQ-C visual imagery analysis}

The ANOVA revealed significant main effects of imagery ability, $F(1,44)=1061.9, p$ $<.01, \eta_{\mathrm{p}}{ }^{2}=0.96$, and climate, $F(1,44)=11.099, p<.01, \eta_{\mathrm{p}}{ }^{2}=0.20$. Post-hoc Newman-Keuls tests revealed that participants had better visual imagery MIQ-C mean scores in TC than in $\mathrm{NC}$, and that poor imagers had worse visual imagery MIQ-F mean scores than good imagers. Moreover, the ANOVA revealed a significant interaction between climate condition and imagery ability, $F(1,44)=19.531, p<.01, \eta_{\mathrm{p}}{ }^{2}=0.31$. Post-hoc Newman-Keuls test revealed that poor imagers had significant better visual imagery MIQ-C mean scores in TC than in NC (Figure 3). However, the ANOVA did not reveal any significant main effect of gender, $F(1$, $44)=0.465, p=.498, \eta_{\mathrm{p}}{ }^{2}=0.01$, or interactions between imagery ability and gender, $F(1,44)$ $=0.511, \mathrm{p}=.478, \eta_{\mathrm{p}}{ }^{2}=0.01$, climate condition and gender, $F(1,44)=0.106, p=.746, \eta_{\mathrm{p}}{ }^{2}=$ 0.00 , and climate condition and imagery ability and gender, $F(1,44)=1.999, p=.164, \eta_{\mathrm{p}}{ }^{2}=$ 0.04 . 
Figure 3 near here

\section{MIQ-C kinaesthetic imagery analysis}

The ANOVA revealed a significant main effect of imagery ability, $F(1,44)=741.89$, $p<.01, \eta_{\mathrm{p}}{ }^{2}=0.94$. Post-hoc Newman-Keuls test revealed that poor imagers had worse kinaesthetic imagery MIQ-C mean scores than good imagers. Moreover, the ANOVA revealed a significant main effect of climate, $F(1,44)=38.449, p<.01, \eta_{\mathrm{p}}{ }^{2}=0.46$. Post-hoc Newman-Keuls test revealed that participants had worse kinaesthetic imagery MIQ-C mean scores in TC than in NC (Figure 4). However, the ANOVA did not reveal any significant main effect of gender, $F(1,44)=0.0841, p=.772, \eta_{\mathrm{p}}{ }^{2}=0.00$, or interactions between imagery ability and gender, $F(1,44)=0.270, p=.606, \eta_{\mathrm{p}}{ }^{2}=0.00$, climate conditions and gender, $F(1,44)=1.186, p=.282, \eta_{\mathrm{p}}^{2}=0.02$, climate conditions and imagery ability, $F(1,44)$ $=0.299, p=.587, \eta_{\mathrm{p}}^{2}=0.00$, and climate conditions and imagery ability and gender, $F(1,44)$ $=0.546, p=.464, \eta_{\mathrm{p}}^{2}=0.01$.

Figure 4 near here

\section{Discussion}

The aim of this original study was to evaluate whether tropical climate differently influences participants' imagery ability when using Creole versus French MIQ validated versions. As sensation of fatigue, thermal comfort and sensation do not statistically differently influence gender or participants in each specific environmental condition (NC vs. TC), the influence of the latter variable can be easily interpreted. The results of this original study showed that participants had worse visual and kinaesthetic MIQ-F and kinaesthetic MIQ-C imagery scores in TC than in NC, but had better visual imagery MIQ-C scores in TC than in 
NC. Moreover, poor imagers had significant lower kinaesthetic imagery MIQ-F scores in TC than in NC, and had significant better visual imagery MIQ-C scores in TC than in NC. The results are discussed in the following sections.

\section{Climate and mental imagery}

The results evidenced a significant main effect of the climate: Participants had worse visual and kinaesthetic MIQ-F and kinaesthetic MIQ-C imagery scores in TC than in NC. This result confirmed those recently obtained by Robin et al. (2017) during which participants fulfilled the Movement Imagery Questionnaire Revised (Hall \& Martin, 1997) and the a mental rotation test and that showed that TC negatively influenced mental rotation, motor imagery and imagery ability. Similar results were observed during heat exposure in studies using different complex tasks (Hocking et al., 2001; Robin \& Coudevylle, 2018; Robin et al., 2019). The Maximal Adaptability Model (Hancock \& Warm, 1989) that assumes that heat exerts its detrimental effects on performance by competing for and eventually draining attentional resources could explain these results. Indeed, it has been proposed that the normative zone is the zone of comfort wherein cognitive adjustments to task demands are easily accomplished and performance is at near optimal level (Hancock \& Vasmatzidis, 2003). As the level of environmental stress increases, by increasing temperature and humidity for examples, attentional resources are progressively drained. For example, Chase, Karwowski, Benedict, Quesade, and Irwin-Chase (2005) reported a poor dual-task performance at $30^{\circ} \mathrm{C}$ or $35^{\circ} \mathrm{C}$ and observed that participants were being unable to successfully allocate their attention to the tasks. In line with the Global Workspace theory (Baars, 1997), Hocking and collaborators (2001) proposed that the performance would decrease when the total resources are insufficient for both the thermal stress (i.e., TC) and the task. It was probably the case when participants had to realize visual or kinaesthetic imagery in the MIQF and kinaesthetic imagery in the MIQ-C. However, the fact that participants had better visual 
imagery MIQ-C scores in TC than in NC might seem surprising. This result will be discussed in the following section.

\section{Language and mental imagery}

Participants of this study were French-Creole bilingual Guadeloupean teachers. The fact that they had better visual imagery MIQ-C scores in TC than in NC whereas the opposite was observed for the visual imagery with the MIQ-F and kinaesthetic imagery for the MIQ-C and the MIQ-F seems to indicate that Creole and French, although sharing common brain structures also activates different neural pathways specific to each language. These results seem coherent with the case study of Massina et al. (2000) who noticed a differential recovery of French and Creole for a patient who followed six months of reeducation in French. The authors observed a better recovery of Creole than re-educated French and found an interpretation in linguistic structures (lexical, morphophonologic, morphosyntaxic), but also in the distribution of main areas for language of the Creole. According to Bialystok (2017), bilingualism changes the brain structures that underlie language processing, and also has the potential to modify brain and cognitive systems more generally. The difference between bilinguals was also showed in Ardila and Ramos (2010) study who observed that during normal aging there is a more rapid decline of the second than the first language, and elder ones tend clearly to prefer using the first language. They proposed that life experiences may be associated with the use of a specific language, and life memories are also associated with the contextual language existing when the memory was acquired. Finally, Monaco, Jost, Gygax, and Annoni (2019) evoked that understanding how the first and second languages are represented in the bilingual's brain and how they are intertwined will favour diagnosing and rehabilitation strategies.

We can wonder about why visual imagery was facilitated in TC when imagery instructions were given in Creole, a climate that normally could cause a decrease of 
performance. According to Michelot (2000), Creole is a language made by images. We might presume that Creole could particularly facilitate mental visual imagery particularly because of shared neural structures (Gallese \& Lakoff, 2005). Indeed, Anciaux and collaborators (2002, 2005) showed an effect of the language on mental movement imagery capacities, the value of imaging the words and the performances of motor reminding with French-Creole bilinguals. For example, the language of presentation of the instructions seems to influence the evocation of mental images and therefore, to increase the memory capacities and the motor reminding of a series of actions (Anciaux, 2007). ). Indeed, as previously evoked, the language embodied (Rueschemeyr et al. 2010) and intertwined to the motor system (Stins et al., 2017). These singular language effects could also be situated at the level of the mobilization of the motivation, attention, emotion, memory, and vision (Byalistok, 2017; Mishra, Srinivasan, \& Huettig, 2015). Language mediates not only the social relationship systems but also the control of cognitive processes (Ardila \& Ramos, 2010; Mishra, 2018) and the use of one additional language is reflected in the pattern of brain organization and activity (Byalistok, 2017). Moreover, we can suppose that when participants learned Creole, they built a representation including environmental elements as climate and the fact to be in TC during visual imagery with the MIQ-C may have facilitated or not limited the access to this representation. Indeed, in the sport domain, Guillot, Collet, and Dittmar (2005) investigated the effectiveness of motor imagery when performed in a context close to actual practice situations rather than in a neutral environment in a table tennis task. They observed that environmental conditions (i.e., tactile, proprioceptive and auditory information) helped athletes to visualize and feel sensations elicited by actual practice. Some environmental conditions could therefore have a beneficial effect on motor imagery as NC for mental imagery with French visual and kinaesthetic imagery instructions or TC as seem to indicate the result of the participants who realized visual imagery with Creole instructions. Participants 
of the current study were born in Guadeloupe except for 5 of them who arrived when they were less than 5 years old. Therefore, statistical analysis including this element as between factors can't be done (given the very small size of the latest group). However, it would be interesting to evaluate if French-Creole bilingual people who learned Creole out of a tropical climate would benefit from this climate condition when realizing visual imagery with Creole instructions in TC. Moreover, according to Ardila and Ramos (2010), research has supported the assumption that using two or more different languages can frequently provide cognitive advantages. Costa, Hernández and Sebastián-Gallés (2008) considered that three different attentional networks can be distinguished: Alerting, orienting and executive control. Comparing monolingual and bilingual subjects, the authors found that bilingual participants were not only faster in performing different attention tasks, but also more efficient in the alerting and executive control networks. As bilingualism can exert beneficial influence in the attainment of efficient attentional mechanisms for example (Mishra, Srinivasan, \& Huettig, 2015), it should also be interesting to compare the visual imagery MIQ-C scores of the participants of the current study with those of monolingual Creole speakers as Haitians living in TC in order to assess the effect of bilingualism on visual imagery. We could also suggest that Creole should appear, for bilinguals, as a cognitive load reduction. TC should represent a cognitive load (e.g., thermal) whereas Creole seems to bring a kind of comfort zone or cognitive facilitation that reduces this load. Further research is needed to evaluate the influence of TC on attentional resource.

\section{Climate, language and imagery ability}

Despite the impact that imagery can have on performance and learning, an individual ability to create and control images can determine the effectiveness of its use (Guillot \& Collet, 2008). Besides showing main effect of the climate, two significant interactions between imagery ability and climate condition were observed in the current study. First, the 
results revealed that poor imagers had significant lower kinaesthetic imagery MIQ-F scores in TC than in NC. This imagery ability effect is consistent with those of Logie, Pernet, Buonocore, and Della Sala (2011) in a mental rotation task, Guillot et al. (2009) recording autonomic nervous response and measuring the activation of cerebral structures and Robin et al. (2007) in a tennis task, for examples. In the latter study, the authors proposed that poor imagers can benefit an imagery practice, as kinaesthetic imagery. However, it is supposed that they needed more trials to become as effective as good imagers as observed in the study of Goss and collaborators (1986) and to previously developed a sensory-specific representation of actions to successfully employ motor imagery as suggested by Toussaint et al. (2010). The fact that poor imagers had lower kinaesthetic imagery MIQ-F scores in TC than in NC, whereas good imagers performance were not affected should be explained by the addition of more difficulties to generate a vivid and accurate kinaesthetic images of action (for poor imagers) in TC which imposes to them a supplementary constraint in term of cognitive resources. We supposed that TC represent a higher level of stress for poor imagers realizing kinaesthetic imagery and the depletion of cognitive resources results in a progressive decline of performance efficiency in mental imagery. On the contrary, the good imagers have probably more efficiently used the remaining resources using adaptive strategies such as attentional focus (Robin \& Coudevylle, 2018).

Secondly, another significant interaction between imagery ability and climate condition revealed that poor imagers had significant better visual imagery MIQ-C scores in TC than in NC. As evoked in the language section, Creole is a language made by images (Michelot, 2000) that seems to facilitate the use of mental visual imagery. The Creole is most of the time learnt in TC places. As proposed by Guillot et al. (2005), an environment closed to the one in which the task was learnt seems to favor the benefits of imagery. That's why we can presume that TC can favor the use of visual imagery when the imagery instructions are in 
Creole in particular for poor imagers. Indeed, good imagers performance was not influenced by the climate when realizing visual imagery with Creole instructions. It is likely that the remaining resources of good imagers were sufficient to obtain a successful outcome. The performance in mental imagery would have been deteriorated only if the total resources had been insufficient for both the task and the climate effect.

Finally, the cognitive dissonance theory that concerns the dynamic interplay of cognition, emotion, and motivation (Festinger, 1957) could be used to explain the results. Indeed, according to Harmon-Jones and Harmon-Jones (2002), when dissonant information is encountered, a negative emotive state causes the person to engage in cognitive work to support the commitment. We can presume that Creole being associated with TC contains less dissonance (as French in NC), particularly during visual imagery, and thus disturb less the participants than Creole in NC or French in TC.

The results of the present study reporting that visual and kinaesthetic imagery MIQ-F scores and kinaesthetic imagery MIQ-C scores were negatively affected by TC, whereas visual imagery MIQ-C was positively affected by TC, prompt us to question of the imagery ability stability depending on environmental conditions and imagery language instructions. Further research will be realized in our laboratory in order to examine how these might predict the success of an imagery intervention in tropical climate: For example, in school task (e.g., mental rotation in mathematics) or in sports (e.g., tennis) that are realized in TC condition, the instruction to realize visual imagery, should permit better acquisition, learning or precision, if it is done in Creole than in French on French-Creole bilinguals.

\section{Gender effect}

For decades, gender has aroused considerable debate (Koslow, 2004). Many authors evidenced that females and males differ in their imagery generating capabilities (Ozel, Molinaro, \& Larue, 2001; Taktek, 2004) and reported differences in cortical activation 
patterns and most especially hemispheric lateralization of brain activity (Seurinck, Vingerhoets, de Lange, \& Achten, 2004). The "psychosocial" variety (stereotype threat, sexrole identification, experience and socialization) and the "biological" variety (e.g., sexual hormones) are the two main causes used to explain these gender differences (Titze, Jansen, \& Heil, 2010). It is possible that because all the participants were teachers, the "psychosocial" variety was limited. Moreover, the fact that gender effect was not observed could be explained by the number of the participants selected in this study (i.e., 96) with more women $(N=66)$ than men $(N=30)$. Indeed, in primary schools, women represent $80 \%$ of all the teachers. However, the results of the literature are inconsistent and many authors using the MIQ (Williams et al., 2012), the MIQ-R (Lorant \& Nicolas, 2004), the MIQ-F (Lorant \& Gaillot, 2003), or the MIQ-C (Anciaux et al., 2002) have already observed that it does not exist a significant difference between men and women as regards motor imagery ability. This finding was corroborated in our sample.

\section{Limitations of this study}

The fact that fatigue, thermal comfort and sensation were assessed by only a single self-report item, unless being the most frequently used method in the literature (Lan et al., 2008), is a limit. Further research using more complex fatigue subjective estimation or thermal comfort evaluation is needed.

Another limit could be the use of self-reported questionnaire. The choice of the MIQ-F and MIQ-C was done because they can be fulfilled everywhere (school or playground). Moreover the two questionnaires are validated and the most commonly used French and Creole tests (Anciaux et al., 2002; Robin \& Coudevylle, 2018). Further research using more objective measures will be realized in our laboratory.

\section{Conclusion}


This original study highlights the necessity to measure participants' imagery ability, to take the environmental conditions (e.g., climate), and to consider the language instruction when realizing mental imagery interventions. By showing significant differences in the MIQC scores for kinaesthetic imagery and in the MIQ-F scores for visual and kinaesthetic imagery between TC and NC, the present study confirms the results observed in the literature (Gaoua, 2010) and could be interpreted as additional support for the relative resistance of working memory to heat stress. However, the fact that visual imagery MIQ-C scores were positively affected by TC seems to indicate that it is important to take the environment in which a language of imagery instruction was learnt into account. Imagery ability stability seems to depend of environmental condition and also language instruction.

\section{Acknowledgments}

The authors would like to acknowledge all the participants of the study.

\section{Conflicts of Interest}

None declared

\section{References}

Abutalebi, J., \& Green, D. W. (2007). Bilingual language production: The neurocognition of language representation and control. Journal of Neurolinguistics, 20, 242-275.

Anciaux, F. (2003). L'enfant, le créole et l'EPS aux Antilles françaises : Une approche pluridisciplinaire du bilinguisme dans les apprentissages moteurs. Thèse de Doctorat non publiée. Guadeloupe : Université des Antilles et de la Guyane.

Anciaux, F. (2007). Langue de présentation des consignes et performances motrices chez des bilingues français/créole aux Antilles françaises. Revue Canadienne des Sciences $d u$ Comportement, 39, 2-12. 
Anciaux, F., Alin, C., Le Her, M., \& Mondor, R. (2002). L’influence de la langue sur la capacité d'imagerie du mouvement. STAPS, Revue Internationale des Sciences du Sport et de l'Education Physique, 23, 81-94. doi:10.3917/sta.058.0081

Anciaux, F. Caliari, P., Alin, C., Le Her, M., \& Fery, Y.-A. (2005). Imagerie visuelle et rappel moteur : Effet du bilinguisme français/créole. Psychologie Française, 50(4), 419-436. doi:10.1016/j.psfr.2005.05.011

Ardila, A., \& Ramos, E. (2010). Bilingualism and aging. Perspectives on communication disorders and sciences in culturally and linguistically diverse populations, 17, 74-81. doi:10.1044/cds17.3.74

Baars, B. J. (1997). In the theatre of consciousness. Global Workspace Theory. A rigorous scientific theory of consciousness. Journal of Consciousness Studies, 4, 292-309. doi:10.1006/cog.1997.0307

Berg, R., Inaba, K., Sullivan, M., Okoye, O., Siboni, S., Minneti, M., Teixeira, P., \& Demetriades, D. (2015). The impact of heat stress on operative performance and cognitive function during simulated laparoscopic operative tasks. Surgery Volume, 157, 87-95. doi:10.1016/j.surg.2014.06.012

Bialystok E. (2017). The bilingual adaptation: How minds accommodate experience. Psychological bulletin, 143(3), 233-262. doi:10.1037/bu10000099

Chase, B., Karwowski, W., Benedict, M., Quesade, P., \& Irwin-Chase, H. (2005). Effects of thermal stress on dual task performance and attention allocation. Journal of Human Performance in Extreme Environments, 8. doi:10.7771/2327-2937.1039

Coudevylle, G. R., Sinnapah, S., Popa-Roch, M., Hue, O., \& Robin, N. (in press). Impact of cold water intake on environmental perceptions, affects, and attention as a function of climate condition. American Journal of Psychology. 
Coudevylle, G. R., Sinnapah, S., Robin, N., Collado, A., \& Hue, O. (2019). Conventional and alternative strategies to cope with the subtropical climate of Tokyo 2020: Impacts on psychological factors of performance. Frontiers in Psychology, 10, 1279. doi: 10.3389/fpsyg.2019.01279

Costa, A., Hernández, M., \& Sebastián-Gallés, N. (2008). Bilingualism aids conflict resolution: Evidence from the ANT task. Cognition, 106, 59-86.

De Baene, W., Duyck, W., Brass, M., \& Carreiras, M. (2015). Brain circuit for cognitive control is shared by task and language switching. Journal of Cognitive Neuroscience, 27, $1752-1765$.

Durizot Jno-Baptiste, P. (1991). La représentation du concept de la langue à travers la langue créole. Etudes Guadeloupéennes, 4, 133-153.

Festinger, L. (1957). A theory of cognitive dissonance. Stanford, CA: Stanford University Press.

Fergusson, C. (1959). Diglossia. Word, 15, 325-340.

Gallese, V., \& Lakoff, G. (2005). The brain's concepts: The role of the sensory-motor system in conceptual knowledge. Cognitive Neuropsychology, 22, 455-479. doi: $10.1080 / 02643290442000310$

Gaoua, N. (2010). Cognitive function in hot environments: A question of methodology. Scandinavian Journal of Medecine and Science in Sports, 20, 60-70. doi:10.1111/j.1600-0838.2010.01210.x

Gauvin, A. (1977). Du créole opprimé au créole libéré, défense de la langue réunionnaise. Paris : L'Harmattan.

Giraud, M., Gani, L., \& Manesse, D. (1992). L’école aux Antilles. Paris : Karthala. 
Guillot, A., \& Collet, C. (2008). Construction of the motor imagery integrative model in sport: A review and theoretical investigation of motor imagery use. International Review of Sport and Exercise Psychology, 1, 31-44.

Guillot, A., Collet, C., \& Dittmar, A. (2005). Influence of environmental context on motor imagery quality. Biology of Sport, 22, 215-226.

Guillot, A., Louis, M., \& Collet, C. (2009). Neural mechanisms for expertise in mental imagery. Cognitive Sciences, 4, 31-48.

Goss, S., Hall, C. R., Buckolz, E., \& Fishburne, G. J. (1986). Imagery ability and the acquisition and retention of movements. Memory and Cognition, 14, 469-477. doi:10.3758/BF03202518

Hall, C. R., Bernoties, L., \& Schmidt, D. (1995). Interference effects of mental imagery on a motor task. Brain Journal of Psychology, 86, 181-190. doi:10.1111/j.20448295.1995.tb02555.x

Hall, C., \& Martin, K. (1997). Measuring movement imagery abilities: A revision of the Movement Imagery Questionnaire. Journal of Mental Imagery, 21, 143-154.

Hall, C. R., \& Pongrac, J. (1983). Movement Imagery Questionnaire. London, Ontario: University of Western Ontario.

Hamers, J., \& Blanc, H. (2000). Bilinguality and bilingualism. Cambridge: Cambridge University Press.

Hancock, P., \& Vasmatzidis, I. (2003). Effects of heat stress on cognitive performance: The current state of knowledge. International Journal of Hyperthermia, 19, 355-372. doi:10.1080/0265673021000054630

Hancock, P. A., \& Warm, J. S. (1989). A dynamic model of stress and sustained attention. Human Factors, 31, 519-37. doi:10.7771/2327-2937.1024 
Harmon-Jones, E., \& Harmon-Jones, C. (2002). Testing the action-based model of cognitive dissonance: The effect of action orientation on postdecisional attitudes. Personality and Social Psychology Bulletin, 28, 711-723.

Hernandez, A., Dapretto, M., Mazziotta, J., \& S., Bookheimer. (2001). Language switching and language representation in Spanish-English bilinguals: An fMRI study. Neuroimage, 14, 510-520.

Hocking, C., Silberstein, R. B., Lau, W. M., Stough, C., \& Roberts, W. (2001). Evaluation of cognitive performance in the heat by functional brain imaging and psychometric testing. Comparative Biochemistry and Physiology A Molecular Integrative Physiology, 128, 719-734. doi:10.1016/S1095-6433(01)00278-1

Koslow, R. E. (2004). Sex-related differences and visual-spatial mental imagery as factors affecting symbolic motor skill acquisition. Sex Roles, 17, 521-527.

Lan, L., Lian, Z., Liu, W. \& Liu, Y. (2008). Investigation of gender difference in thermal comfort for Chinese people. European Journal of Applied Physiology, 102, 471-480. doi:10.1007/s00421-007-0609-2

Logie, R. H., Pernet, C. R., Buonocore, A., \& Della Sala, S. (2011). Low and high imagers activate networks differentially in mental rotation. Neuropsychologia, 49, 3071-3077. doi:10.1016/j.neuropsychologia.2011.07.011

Lorant, J., \& Gaillot, L. (2003). Validation de la version française du Movement Imagery Questionnaire (MIQ) [Validation of the French version of the Movement Imagery Questionnaire (MIQ)]. Canadian Journal of Behavioural Science, 36, 30-35. doi:10.1037/h0087213

Lorant, J., \& Nicolas, N. (2004). Validation de la traduction française du Movement Imagery Questionnaire - Revised (MIQ-R) [Validation of the French translation of the 
Movement Imagery Questionnaire-Revised (MIQ-R)]. Sciences et Motricité, 53, 5768. doi:10.3917/sm.053.0057

Massina, C., Le Gall, D., Aubin, G., Mazaux, J. M., Galanthe, E., Sainte-Foie, S., \& Emile, J. (2000). Une observation de la récupération différentielle des deux langues chez une patiente aphasique bilingue français/créole guadeloupéen. Annales de Réadaptation Médicale et Physiologie, 43, 450-464. doi: 10.1016/S0168-6054(00)00049-0

McNeish, D. (2018). Thanks coefficient alpha, we'll take it from here. Psychological Methods, 23, 412-433. doi: 10.1037/met0000144

Mechelli, A., Crinion, J. T., Noppeney, U., O'Doherty, J., Ashburner, J., Frackowiak, R. S., \& Price, C. J. (2004). Neurolinguistics: Structural plasticity in the bilingual brain. Nature, 431, 757-785. doi:10.1038/431757a

Michelot, I. (2000). La situation sociolinguistique de la Martinique : enquête. Mofwaz, 5, 7185.

Mishra, R. K. (2018). Bilingualism and cognitive control. New Delhi, Springer International Publishing.

Mishra, R. K., Srinivasan, N., \& Huettig, F. (2015). Attention and vision in language processing. New Delhi, Spinger India.

Monaco, E., Jost, L. B., Gygax, P. M., \& Annoni, J-M. (2019). Embodied Semantics in a Second Language: Critical Review and Clinical Implications. Frontiers in Human Neurosciences, 13, 110. doi: 10.3389/fnhum.2019.00110

Ozel, S., Molinaro, C., \& Larue, J. (2001). Influence of sport on gender differences in spatial imagery. Homeostasis in Health and Disease, 41, 169-175. doi:0.2466/pms.2002.95.3f.1141

Qian, S., Li, M., Li, G., Liu, K., Li, B., Jiang, Q., Li, L., Yang, Z., \& Sun, G. (2015). Environmental heat stress enhances mental fatigue during sustained attention task 
performing: Evidence from an ASL perfusion study. Behavioral Brain Research, 280, 6-15. doi:10.1016/j.bbr.2014.11.036

Ramsey, J., \& Kwon, Y. (1992). Recommended alert limits for perceptual motor loss in hot environments. International Journal of Industrial Ergonomics, 9, 245-257. doi:10.1016/0169-8141(92)90018-U.

Robin, N., Collado, A., Sinnapah, S., Rosnet, E., Hue, O., \& Coudevylle, G.R. (2019). The Influence of Tropical Climate on Cognitive Task Performance and Aiming Accuracy in Young International Fencers. Journal of Human Performance in Extreme Environments, 15(1), 4.

Robin, N., Coudevylle, G.R. (2018). The influences of tropical climate and load on mental chronometry moderated by imagery ability. International Journal of Sport Psychology, 49, 240-255.

Robin, N., Coudevylle, G. R., Sinnapah, S., \& Hue, O. (2017). Effects of tropical climate on mental rotation: The role of imagery ability. American Journal of Psychology, 130, 455-465. doi: 10.5406/amerjpsyc.130.4.0455

Robin, N., Dominique, L., Toussaint, L., Blandin, Y., Guillot, A., \& Le Her, M. (2007). Effects of motor imagery training on returning serve accuracy in tennis: The role of imagery ability. International Journal of Sport and Exercise Psychology, 2, 177-188. doi:10.1080/1612197X.2007.9671818

Rueschemeyer, S. A., Lindemann, O., van Rooij, D., van Dam, W., \& Bekkering, H. (2010). Effects of intentional motor actions on embodied language processing. Experimental Psychology, 57, 260-266. doi: 10.1027/1618-3169/a00003

Salati, E., Lovejoy, T. E., \& Vose, P. B. (1983). Precipitation and water recycling in tropical rain forests with special reference to the amazon basim. Environmentalist, 3, 67-72. doi: 10.1007/BF02240058 
Seiler, B., Monsma, E., \& Newman-Norlund, R. (2015). Biological Evidence of Imagery Abilities: Intraindividual Differences. Journal of Sport and Exercise Psychology, 37, 421-35. doi:10.1123/jsep.2014-0303

Seurinck, R., Vingerhoets, G., de Lange, F. R., \& Achten, E. (2004). Does egocentric mental rotation elicit sex differences? Neuroimage, 23, 1440-1449. doi:10.1016/j.neuroimage.2004.08.010

Singh, J. P., \& Mishra, R. K. (2015). Effect of bilingualism on anticipatory oculomotor control. International Journal of Bilingualism 20(5), 550-562.

Stins, J., Marmolejo-Ramos, F., Wenker, E., Hulzinga, F., \& Cañal-Bruland, R. (2017). Words that move us: The effects of sentences on body sway. Advances in Cogntive Psychology, 13(2), 56-165. doi: 10.5709/acp-0215-9.

Taktek, K. (2004). The effects of mental imagery on the acquisition of motor skills and performance: A literature review. Journal of Mental Imagery, 28, 79-114.

Titze, C., Jansen, P., \& Heil, M. (2010). Mental rotation performance and the effect of gender in fourth graders and adults. European Journal of Developmental Psychology, 7, 432444. doi:10.1080/17405620802548214

Toussaint, L., Robin, N., \& Blandin, Y. (2010). On the content of sensorimotor representations after actual and motor imagery practice. Motor Control, 14, 159-175.

Vasseur, M. T. (1997). Le cas de l'adulte bilingue dans les dispositifs de formation en Guadeloupe : un exemple des tensions à l'œuvre dans une communauté créole. Etudes Créoles, 20, 38-45.

Véronique, G. D. (2000). Créole, créoles français et théories de la créolisation. Information Grammaticale, 85, 33-38. doi:10.3406/igram.2000.2769

White, A., \& Hardy, L. (1998). An in-depth analysis of the uses of imagery by high-level slalom canoeists and artistic gymnasts. Sport Psychologist, 12, 387-403. 
Williams, E., Cooley, J., \& Cumming, J. (2013). Layered stimulus response training improves motor imagery ability and movement execution. Journal of Sport and Exercise Psychology, 35, 60-71. Retrieved from http://journals.humankinetics.com/jsep

Williams, E., Cumming, J., Ntoumanis, N., Nordin-Bates, S. M., Ramsey, R., \& Hall, C. R. (2012). Further validation and development of the movement imagery questionnaire. Journal of Sport and Exercise Psychology, 34, 621-646.

Wyon, D. P., Andersen, I. \& Lundqvist, G. R. (1972). Spontaneous magnitude estimation of thermal discomfort during changes in the ambient temperature. Journal of Hygiene, 70, 203-221.

Xiong, J., Lian, Z., Zhou, X., You, J. and Lin, Y. (2015). Effects of temperature steps on human health and thermal comfort. Building and Environment, 94, 144-154.

Zhao, T., Huang, Y., Cheng, D., Jiao, L., Marmolejo-Ramos, F., Wang, R., \& Xie, J. (in press). The modality switching costs of Chinese-English bilinguals in the processing of L1 and L2. Quarterly Journal of Experimental Psychology. doi:

$10.1177 / 1747021819878089$ 
Table 1

Subjective assessments on feeling of fatigue and thermal comfort and in neutral and tropical climates

Climate condition

Tropical climate

Neutral climate

Feeling of fatigue [fully alert (1); very lively (2); okay (3); a little tired (4); moderately tired (5); extremely tired (6); completely exhausted (7)]
Mean, $(S D),[\mathrm{CI}]$
$4.32(1.01)[4.10,4.56]$
$3.18(1.09)[2.93,3.43]$
Anova, (effect size)
$F(1,94)=70.81^{* *},(\eta 2=0.42)$

Thermal comfort [comfortable (1); slightly uncomfortable; (2) uncomfortable; (3) very uncomfortable (4)]
Mean, $(S D),[\mathrm{CI}]$
$3.74(0.81)[3.65,3.85]$
$1.04(0.22)[1.00,1.11]$
Anova, (effect size)
$F(1,94)=2457.90 * *,(\eta 2=0.99)$

Thermal sensation [hot (3); warm (2); slightly warm (1); neutral (0); slightly cool (-1); cool $(-2)$; cold $(-3)]$
Mean, $(S D),[\mathrm{CI}]$
$2.71(0.57)[2.56,2.82]$
$-0.39(0.69)[-0.53,-0.22]$
Anova, (effect size)
$F(1,94)=945.63 * *,(\eta 2=0.90)$

Notes. The results shown are averages, standard deviation (in brackets) and Confidence Level Cronbach's alpha with a 95\% confidence interval [CI].** Significant differences $(p<.05)$ of the main effects of climate condition in ANOVAs using the gender (female vs. male) as between-participants factor and the climate condition (TC vs. NC) as within-participants factor. 
Figure 1
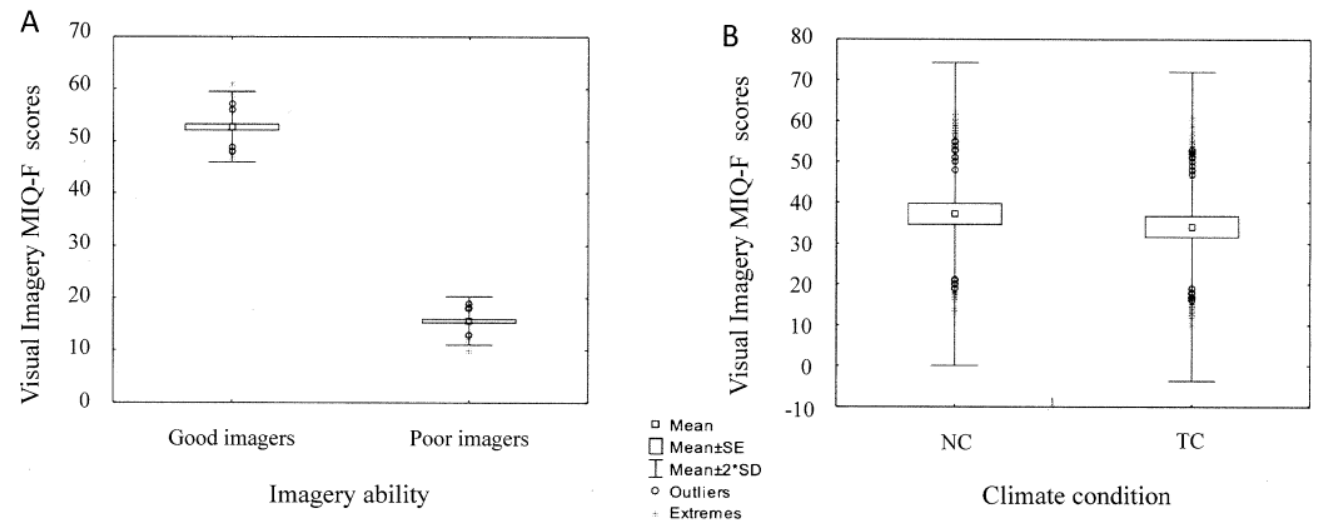
Figure 2

A
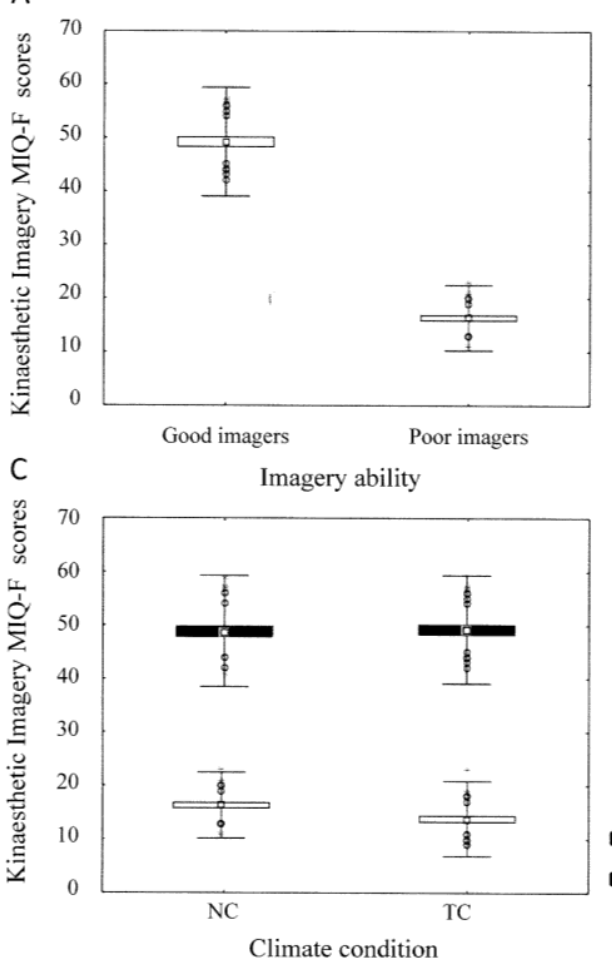

Climate condition

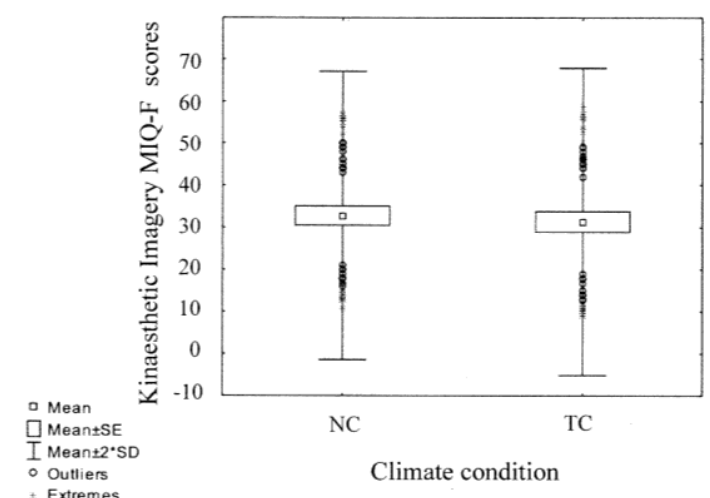

- Good imagers

Poor imagers

Mean 1 SE

I Meant2'SD

- Outliers 
Figure 3

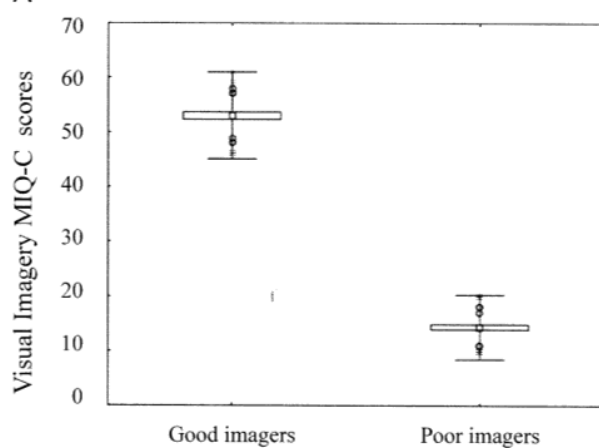

C

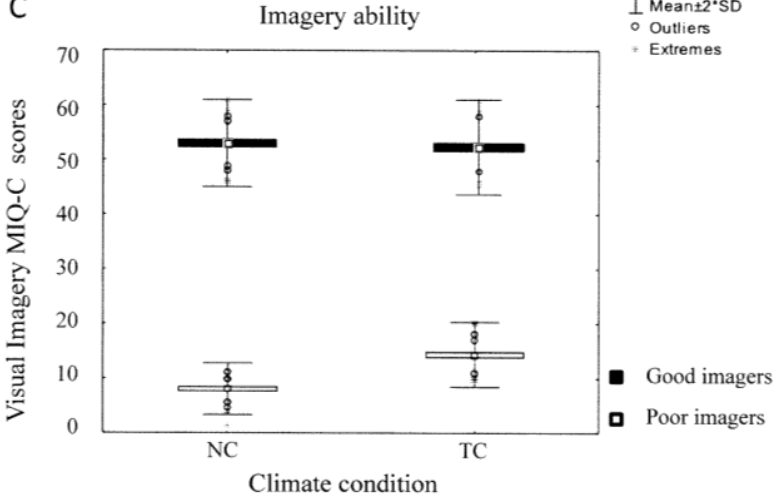

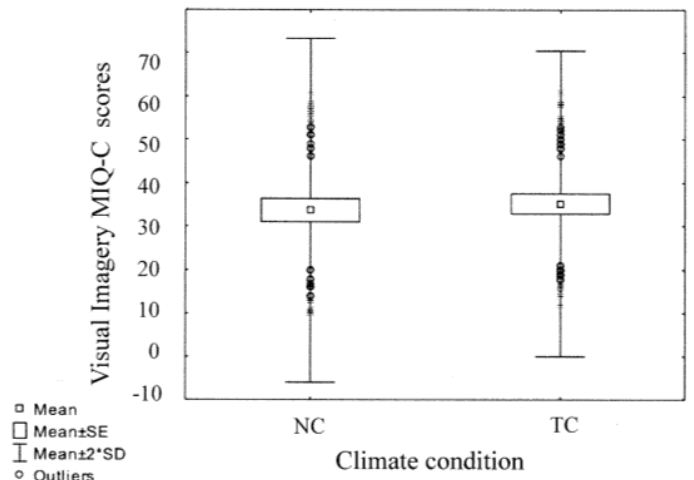


Figure 4

A

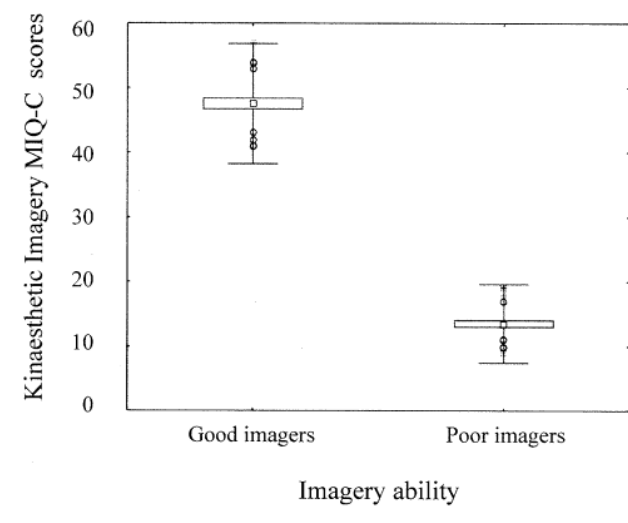

B

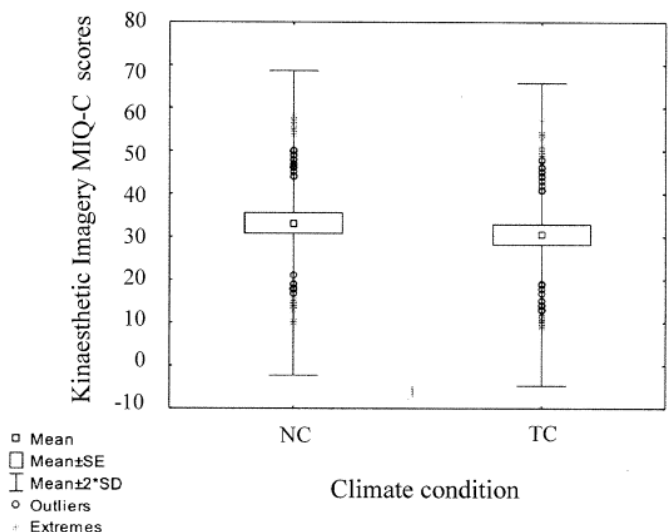




\section{Figure Captions}

Figure 1. Main effects of imagery ability (A) and climate (B) on visual imagery MIQ-F scores. $\mathrm{TC}=$ Tropical Climate, $\mathrm{NC}=$ Neutral Climate. I-beams indicate the $95 \%$ confidence intervals for the mean values. *Significant difference by ANOVA: $p<.05$.

Figure 2. Main effects of imagery ability (A) and climate condition (B) and Imagery ability $\times$ climate condition interaction $(\mathrm{C})$ on kinaesthetic imagery MIQ-F scores. TC $=$ Tropical Climate, $\mathrm{NC}=$ Neutral Climate. I-beams indicate the 95\% confidence intervals for the mean values. *Significant difference by ANOVA: $p<.05$.

Figure 3. Main effects of imagery ability (A) and climate condition (B) and Imagery ability $\times$ climate condition interaction (C) on Visual imagery MIQ-C scores. TC = Tropical Climate, $\mathrm{NC}=$ Neutral Climate. I-beams indicate the $95 \%$ confidence intervals for the mean values. *Significant difference by ANOVA: $p<.05$.

Figure 4. Main effects of imagery ability (A) and climate condition (B) on kinaesthetic imagery MIQ-C scores. $\mathrm{TC}=$ Tropical Climate, $\mathrm{NC}=$ Neutral Climate. I-beams indicate the $95 \%$ confidence intervals for the mean values. *Significant difference by ANOVA: $p<.05$. 